\title{
HER2 and immunotherapy using monoclonal antibodies in colorectal cancer
}

\section{"The main challenge with regard to HER2-targeted mAb therapy is optimal use of the level and location of expression of tumor HER2 protein overexpression."}

\section{KEYWORDS: colorectal cancer $\approx$ HER2 $\approx$ immunotherapy $\approx$ monoclonal antibodies}

Colorectal cancer (CRC) is a major health problem in both men and women, with a serious incidence and economic burden worldwide [1]. For early stages of the disease, surgery is a very effective treatment. However, CRC is often diagnosed once it has become established and has already extended beyond the bowel (stage II and III) or once already in distant organs (stage IV), owing to the lack of symptoms during initial stages of the disease [2]. Similar to stage I, surgery is the primary treatment for stage II/III and is effective in the removal of the primary tumor. However, in many cases, patients (up to 35\%) develop distant metastasis during follow-up. Therefore, for these stages, adjuvant treatment would be welcome. In stage IV CRC, surgery alone is not effective, making additional treatment necessary. Traditional therapeutic approaches, such as chemotherapy and radiation, for managing CRC in addition to surgery do not demonstrate encouraging outcomes. Therefore, other treatment strategies are needed and approaches such as signaling inhibitors and immunotherapy are promising new tools to treat CRC [3].

For an immunotherapeutical approach, monoclonal antibodies $(\mathrm{mAbs})$ are an attractive option. Compared with conventional chemotherapy, which affects normal cells in addition to cancer cells, mAb therapy has fewer and less-severe adverse effects [4]. Although development is quite laborious and costly, once produced, mAbs can be relatively easily produced in large amounts at clinical grade. Furthermore, mAbs may act at different levels as they may block the function of a protein, but can also activate effector mechanisms of the immune system, including complementdependent cytotoxicity and antibody-dependent cell-mediated cytotoxicity $[4,5]$. There is one essential prerequisite: to be effective, mAbs must be able to reach the target protein; therefore, this must be a membrane protein protruding from the cell surface. Of course, there are additional prerequisites such that this membrane protein should be tumor-specific to prevent damage to other tissues. Several antibodies have been developed for treatment of CRC and were clinically tested. Three mAbs, cetuximab (erbitux, anti-EGF receptor [EGFR], panitumumab (Vectibix ${ }^{\circledR}$, antiVEGF) and bevacizumab (Avastin ${ }^{\circledR}$, anti-VEGF), have been extensively studied for the treatment of CRC and, indeed, were shown to be effective [3,6]. For other tumor types, many different antibodies have been developed. In breast cancer one of the most effective is trastuzumab [7]. Trastuzumab $\left(\right.$ Herceptin $\left.^{\circledR}\right)$ is a recombinant humanized IgG1 $\mathrm{mAb}$ directed against the extracellular domain of HER2, also called Her-2/neu, that is encoded by the ERBB2 gene, which is known as a protooncogene. Trastuzumab was US FDA-approved in 1998 as a single-agent therapy for patients with metastatic breast cancer and demonstrated a dramatic improvement in survival, as well as recurrence rate when used as adjuvant therapy after surgery, but only in cancers that were overexpressing HER2 $[7,8]$. When considering the application of trastuzumab in CRC, we need to know about HER2 expression and its role in CRC.

The ERBB2 gene is localized on chromosome 17q and encodes HER2, a $185-\mathrm{kDa}$ transmembrane glycoprotein receptor molecule with tyrosine kinase activity. HER2 belongs to a family of four homologous proteins (HER1, HER2, HER3 and HER4) that all demonstrate extensive homology to EGFR [9]. HER receptors bind to each other upon binding of a ligand to form homodimers or heterodimers. This dimerization of HER2 in combination with its expression level may determine its cellular location, which can be both at the cell surface or in the cell membrane and intracellularly [10]. Many different ligands are known to bind to HER receptors, but the specific ligand for HER2 is unknown. In 'normal' cell growth,

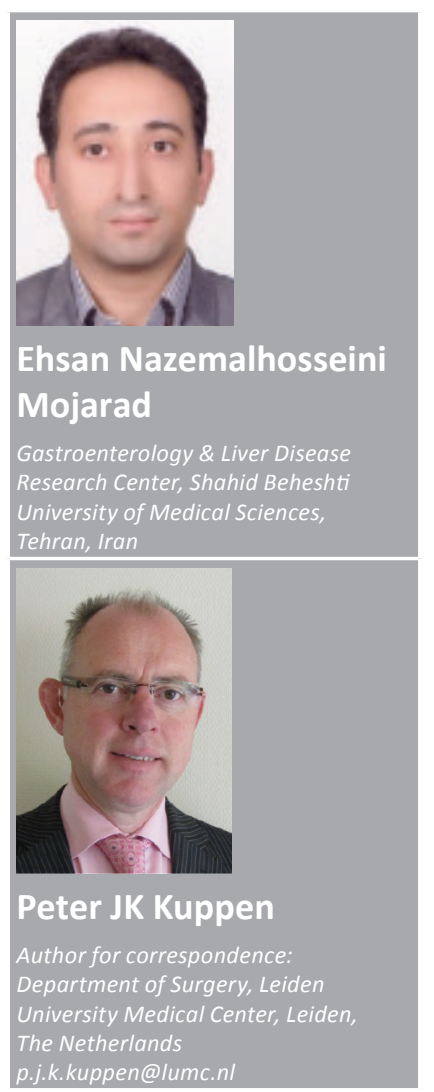

Future fSO $_{\text {part of }}$ 
HER 2 is expressed, a few HER 2 heterodimers are present and HER2-mediated signaling is weak [9]. There seems to be a correlation between genomic amplification, as found in many tumor types, and membranous overexpression, but this needs further study [11]. The mechanism by which HER2 overexpression deregulates different signaling networks in cells is poorly understood, but the important role of overexpression in tumor progression for a variety of human cancers is undisputed [12]. HER2 overexpression occurs not only in breast tumors, but also in other malignancies including CRC, suggesting that trastuzumab could also be effective in CRC [13].

\section{"Compared with conventional chemotherapy, which affects normal cells in addition to cancer cells, monoclonal antibody therapy has fewer and less-severe adverse effects."}

The main challenge with regard to HER2targeted $\mathrm{mAb}$ therapy is optimal use of the level and location of expression of tumor HER2 protein overexpression. Tumors expressing low levels of HER2 are generally unresponsive to trastuzumab and this aspect is critical to the selection of patients for trastuzumab therapy [14]. However, in our opinion, an important criterion should be added. That is that HER2 must be expressed on the tumor cell surface. In cases of overexpression, but with the protein remaining cytoplasmatic, it cannot be expected that mAbs will sufficiently bind to the protein, resulting in no therapeutical response. In breast cancer, HER2 generally seems to be expressed on the cell surface [15]. However, in CRC, the situation is different. Conflicting data exist about the prevalence of HER2 overexpression in CRC, ranging from 0 to $83 \%$ [16]. Most researchers agreed that the differences in expression were probably due to differences in technical approaches, antibodies and scoring protocols, but conclusive data were never presented. Disagreements in evaluation of expression at the nuclear, cytoplasmic and cell surface levels highlights the limitations of immunohistochemical evaluation alone and stresses the need for further evaluation of response to HER2-targeted therapies in tumors displaying overexpression in gene

copy, mRNA and receptor protein [17]. When splitting the results in CRC into membranous and cytoplasmic HER2 overexpression, a clear pattern appears with approximately $5 \%$ of all CRC patients having membranous overexpression and approximately $30 \%$ of the patients having cytoplasmic overexpression $[10,13]$. This suggests that trastuzumab may be effective in CRC patients, but only in a very limited number of patients. Alternatively, lapatinib, a tyrosine kinase inhibitor that blocks tyrosine kinase activity, may be applied. Lapanitib has advantages as it may function intracellularly and also blocks the EGFR pathway, but clinical results using lapanitib, obtained in CRC patients to date, have not been promising [18].

There is no doubt that HER2 can be immunogenic and generate antibodies and activation of $\mathrm{T}$ lymphocytes (including both cytotoxic $\mathrm{T}$ cells and T-helper cells) in vivo [9]. This suggests that HER2 can also be a target for $\mathrm{T}$ cell-directed immunotherapy, as seems to be possible for other 'self' proteins that are overexpressed [19]. For the large group of patients in CRC that demonstrates HER2 overexpression, but with the protein remaining in the cytoplasm, this may be an attractive option that deserves further study $[9,10]$.

In conclusion, trastuzumab may be effective in CRC, but only in tumors with the HER2 protein on their cell membrane, which accounts for approximately $5 \%$ of the patients. Therefore, if applied, patients should be preselected based on their HER2-expression pattern. Many more CRC patients do overexpress HER2, but the protein remains cytoplasmatic. For these patients immunotherapy using a T-cell approach should be considered and developed.

\section{Financial \& competing interests disclosure}

The authors have no relevant affiliations or financial involvement with any organization or entity with a financial interest in or financial conflict with the subject matter or materials discussed in the manuscript. This includes employment, consultancies, honoraria, stock ownership or options, expert testimony, grants or patents received or pending, or royalties.

No writing assistance was utilized in the production of this manuscript.

\section{References}

1 Chu E. Colorectal cancer (CRC) continues to be a major public health problem in the United States and throughout the world. Cancer J. 16(3), 195 (2010).

2 Amri R, Bordeianou LG, Sylla P, Berger DL. Impact of screening colonoscopy on outcomes in colon cancer surgery. JAMA Surg. 148(8), 747-754 (2013).

3 Noguchi T, Ritter G, Nishikawa $H$. Antibody-based therapy in colorectal cancer. Immunotherapy 5(5), 533-545 (2013).

4 Toomey PG, Vohra NA, Ghansah T et al. Immunotherapy for gastrointestinal malignancies. Cancer Control 20, 32-42 (2013).

5 Roskoski R Jr. The ErbB/HER receptor protein-tyrosine kinases and cancer. Biochem. Biophys. Res. Commun. 319, 1-11 (2004).

6 Tol J, Punt CJ. Monoclonal antibodies in the treatment of metastatic colorectal 
cancer: a review. Clin. Ther. 32, 437-453 (2010).

7 Dent S, Oyan B, Honig A et al. HER2targeted therapy in breast cancer: a systematic review of neoadjuvant trials. Cancer Treat. Rev. 39(6), 622-631 (2013).

8 Waldmann TA, Morris JC. Development of antibodies and chimeric molecules for cancer immunotherapy. Adv. Immunol. 90, 83-131 (2006).

9 Baxevanis CN, Sotiropoulou PA, Sotiriadou NN et al. Immunobiology of HER-2/neu oncoprotein and its potential application in cancer immunotherapy. Cancer Immunol. Immunother. 53(3), 166-175 (2004).

10 Blok EJ, Kuppen PJ, van Leeuwen JE et al. Cytoplasmic overexpression of HER2: a key factor in colorectal cancer. Clin. Med. Insights Oncol. 7, 41-51 (2013).
11 Pavlakis K, Kountourakis P, Stathopoulos E et al. HER-2 protein expression, cellular localization, and gene amplification in colorectal carcinoma. Appl. Immunohistochem. Mol. Morphol. 15(4), 441-445 (2007).

12 Berezov A, Greene MI. Towards comprehensive characterization of HER2 overexpression. Mol. Syst. Biol. 2, 55 (2006).

13 Kavanagh DO, Chambers G, O'Grady L et al. Is overexpression of HER-2 a predictor of prognosis in colorectal cancer? BMC Cancer 9 , 1 (2009).

14 Denkert C, Huober J, Loibl S et al. HER2 and ESR1 mRNA expression levels and response to neoadjuvant trastuzumab plus chemotherapy in patients with primary breast cancer. Breast Cancer Res. 15(1), R11 (2013).

15 Burstein HJ. The distinctive nature of HER2positive breast cancers. N. Engl. J. Med. 353(16), 1652-1654 (2005).
16 Schuell B, Gruenberger T, Scheithauer W et al. HER 2/neu protein expression in colorectal cancer. BMC Cancer 6, 123 (2006).

17 Saxby AJ, Nielsen A, Scarlett CJ et al. Assessment of HER-2 status in pancreatic adenocarcinoma: correlation of immunohistochemistry, quantitative real-time RT-PCR, and FISH with aneuploidy and survival. Am. J. Surg. Pathol. 29(9), 1125-1134 (2005).

18 Frank D, Jumonville A, Loconte NK et al. A Phase II study of capecitabine and lapatinib in advanced refractory colorectal adenocarcinoma: a Wisconsin Oncology Network study. J. Gastrointest. Oncol. 3(2), 90-96 (2012).

19 Speetjens FM, Kuppen PJ, Welters MJ et al. Induction of $\mathrm{p} 53$-specific immunity by a $\mathrm{p} 53$ synthetic long peptide vaccine in patients treated for metastatic colorectal cancer. Clin. Cancer Res. 15(3), 1086-1095 (2009). 